\title{
Laser Microdissection of Pancreatic Islets Allows for Quantitative Real-Time PCR Detection of Islet-Specific Gene Expression in Healthy and Diabetic Cats
}

\author{
Malin Öhlund ${ }^{1}$, Petra Franzen ${ }^{2}$, Göran Andersson ${ }^{3}$, Bodil Ström Holst ${ }^{1}$ and Joey Lau ${ }^{2 *}$ \\ ${ }^{1}$ Department of Clinical Sciences, Swedish University of Agricultural Sciences, Box 7054, SE-750 07 Uppsala, Sweden \\ ${ }^{2}$ Department of Medical Cell Biology, Uppsala University, Box 571, SE-751 23 Uppsala, Sweden \\ ${ }^{3}$ Department of Animal Breeding and Genetics, Swedish University of Agricultural Sciences, Box 7023, SE-750 07 Uppsala, Sweden
}

Received: September 24, 2014; Accepted: November 20, 2014; Published: December 05, 2014

*Corresponding author: Joey Lau, Department of Medical Cell Biology, Uppsala University, Box 571, SE-751 23 Uppsala, Sweden, Tel: +46-18-471-4395; Fax: +46-18-471-4059; Email: Joey.Lau@mcb.uu.se

\begin{abstract}
Background: Feline diabetes mellitus shares many similarities with human type 2 diabetes mellitus, including clinical, physiological and pathological features of the disease. The domestic cat spontaneously develops diabetes associated with insulin resistance in their middle age or later, with residual but declining insulin secretion. Humans and cats share largely the same environment and risk factors for diabetes, such as obesity and physical inactivity. Moreover, amyloid formation and loss of beta cells are found in the islets of the diabetic cat, as in humans. Altogether, the diabetic cat is a good model for type 2 diabetes in humans. The aim of the present study was to isolate feline islets using laser microdissection and to develop a quantitative method for detection of mRNA levels in islets of healthy and diabetic cats.

Results: By using the laser microdissection technique, we were able to meticulously sample islets from both healthy and diabetic cats. Insulin staining of separate sections showed many beta cells in islets from healthy cats, whereas few insulin positive cells were found in islets from diabetic cats. By quantitative real-time PCR, mRNA levels of the islet-specific genes INS, PDX1, IAPP, CHGA and IA-2 could be detected in both healthy and diabetic cats.

Conclusions: Laser microdissection allows distinct studies of islets without contamination of acinar cells. Previous attempts in isolating feline islets with different collagenase-based protocols have led to damaged islets or islets coated with exocrine acinar cells, which either way compromise the results obtained from gene expression studies. The use of the laser microdissection technique eliminates these problems as shown in this study. Differences in gene expression between healthy and diabetic cats can reveal underlying mechanisms for beta cell dysfunction and decreased beta cell mass in human type 2 diabetes.
\end{abstract}

Keywords: Beta cell; Type 2 Diabetes mellitus; Felis catus; Gene expression; Islet isolation; Laser microdissection; Pancreatic islets

\section{Abbreviations}

LMD: Laser Microdissection; qPCR: quantitative real-time Polymerase Chain Reaction; T2DM: Type 2 Diabetes Mellitus; BP: Base Pair; INS: Insulin; PDX1: Pancreatic and Duodenal Homeobox 1; CHGA: Chromogranin A; IA-2: Islet Cell Antigen 2; IAPP: Islet
Amyloid Polypeptide; PNLIP: Pancreatic Lipase; ACTB: BetaActin; GAPDH: Glyceraldehyde 3-Phosphate Dehydrogenase; RPS7: Ribosomal Protein S7; IHC: Immunohistochemistry; HRP: Horseradish Peroxidase; DAB: Diaminobenzidine Tetrahydrochloride

\section{Introduction}

Feline diabetes mellitus shares many similarities with Type 2 Diabetes Mellitus (T2DM) in humans, including clinical, physiological and pathological features of the disease. The domestic cat has thus been proposed a valuable animal model for T2DM [1,2]. Cats spontaneously develop diabetes associated with insulin resistance in their middle age or later, with residual but declining insulin secretion. Humans and cats largely share the same environment and also many of the risk factors for diabetes, such as obesity and physical inactivity. The diabetic cat may also develop late complications such as peripheral polyneuropathy, retinopathy, and nephropathy [1-5]. Amyloid deposition in islets, associated with an approximately $50 \%$ loss of beta-cell mass, is described in over $80 \%$ of cats with diabetes, as in human T2DM [6-9]. Amyloid formation is not seen in any of the rodent models of T2DM [1] and is a clear advantage for the feline model. Characterizing molecular mechanisms for beta cell dysfunction and decreased beta cell mass in feline diabetes may elucidate factors and mechanisms responsible for the development of type 2 diabetes in both cats and humans.

It is difficult to isolate feline islets without contamination with exocrine tissue, and it has been suggested that feline islets are particularly difficult to isolate with collagenase digestion because they are delimited with very little peri-islet matrix $[10,11]$. This leads to either damaged islets, or islets coated with acinar cells (referred to in the literature as islet-like cell clusters) $[11,12]$, which either way compromise the results obtained from gene expression studies. The use of the Laser Microdissection (LMD) technique can eliminate some of the problems inherent in the use of collagenase-isolated islets [13]. The technique has been used successfully in human and rodent islet isolations [13- 
17]. LMD can be used selectively to cut out islets without visible contamination of acinar cells, and the technique also avoids some of the problems associated with trauma and stress to the cells by the enzymatic isolation that will cause changes in gene expression [13]. LMD of human beta-cells, recognized by their intrinsic autofluorescence, is performed on pancreatic tissue obtained from heart-beating cadaveric donors or from surgical samples from human pancreases [18]. The drawback with this approach is the long cold ischemia time or the small study material from surgical samples, since the islets only constitute $1-2 \%$ of the pancreas. In the cat, the whole pancreas can be removed from the euthanized animal and immediately snap frozen in liquid nitrogen, which enables us to study islets as close to reality as possible.

The aim of the present study was to develop a technique to isolate feline islets in order to perform gene expression studies in healthy and diabetic cats. This article reports a reliable method to obtain feline islets from both healthy and diabetic cats, with preserved RNA integrity for subsequent gene expression studies.

\section{Material and Methods}

\section{Animals}

Two healthy and two diabetic cats were included in the study. Ethical approval for this study was obtained from the Uppsala Ethical Committee on Animal Experiments (Dnr C 262/12). All cats were euthanized on the owner's request for reasons unrelated to this study. Written consent was obtained from all owners before inclusion in the study. Diabetic cats were diagnosed based on clinical and laboratory findings consistent with persistent hyperglycemia. The concentration of fructosamine in serum is a reflection of mean blood glucose level over the preceding 1 to 3 weeks [19]. One of the diabetic cats (nr. 1) showed typical clinical signs of diabetes for several months prior to diagnosis and had lost more than $20 \%$ of its body weight. This cat also had markedly elevated serum fructosamine levels, $752 \mu \mathrm{mol} / \mathrm{L}$ (ref 190-350) and was euthanized. The second diabetic cat (nr. 2) had a short disease history and presented with only slightly elevated serum fructosamine levels, $461 \mu \mathrm{mol} / \mathrm{l}$, and was euthanized due to reasons other than the diabetes. None of the cats had received insulin treatment. Cats were sedated with different combinations of acepromazine (Plegicil ${ }^{\circledR}$ vet., Pharmaxim), medetomidine (Sedator ${ }^{\circledR}$, Dechra Veterinary Products) and butorphanol (Dolorex vet., Intervet) given subcutaneously, prior to euthanasia with an intravenous overdose of sodium pentobarbital (Allfatal vet., Omnidea). Diagnosis of diabetes was confirmed by postmortem examination and histopathology of the pancreas. Pancreatic sections were also stained with Congo red as previously described [20] to confirm presence of amyloid in diabetic islets (Figure 1). Histopathological examination indicated no infiltration of immune cells in diabetic islets.

\section{Preparation of tissue for laser microdissection}

Immediately after euthanasia the pancreata were surgically excised from the cats under sterile conditions. The islet-dense splenic portion of the pancreas [21] was sectioned and embedded in frozen section medium (Richard-Allan Scientific NEG 50, Thermo Scientific, Kalamazoo, MI, USA) in cryomolds (TissueTek $^{\circledR}$ Cryomold $^{\circledR}$, Sakura Finetek Inc, Torrance, CA, USA) and snap frozen in liquid nitrogen. Mean time from point of death to snap freezing of pancreatic specimens was 13 min (range 10-17 min). Tissue samples were stored in $-80^{\circ} \mathrm{C}$ until cryosectioning.

Frame slides (POL-Membrane $0.9 \mu \mathrm{m}$, Leica Microsystems, Wetzlar, Germany) were exposed to UV-light overnight for cross-linking of the membrane in order to improve cutting of the membrane. The cryostat, including accessories i.e. the sample holder, were cleaned with $70 \%$ ethanol. Brushes for cryosectioning and a glass cuvette with ice cold acetone were put in the cryostat and thereafter the UV-light in the cryostat was switched on for $30 \mathrm{~min} .10 \mu \mathrm{m}$ thick sections were mounted on frame slides and fixed in ice cold acetone for $2 \mathrm{~min}$. The frame slide was then dried with cold air before storage in an RNase free $50 \mathrm{ml}$ tube (Ambion, LifeTechnologies Europe BV, Stockholm, Sweden) in $-80^{\circ} \mathrm{C}$.

The frame slide with pancreas sections was thawed for $30 \mathrm{~s}$ before hydration in nuclease free water (Ambion) for $30 \mathrm{~s}$. RNase free hematoxylin (Arcturus ${ }^{\circledR}$ HistoGene ${ }^{\circledR}$ Staining Solution, Applied Biosystems, Foster City, CA, USA) was applied to the sections for 90 $\mathrm{s}$ and washed away with nuclease free water for $30 \mathrm{~s}$. The sections
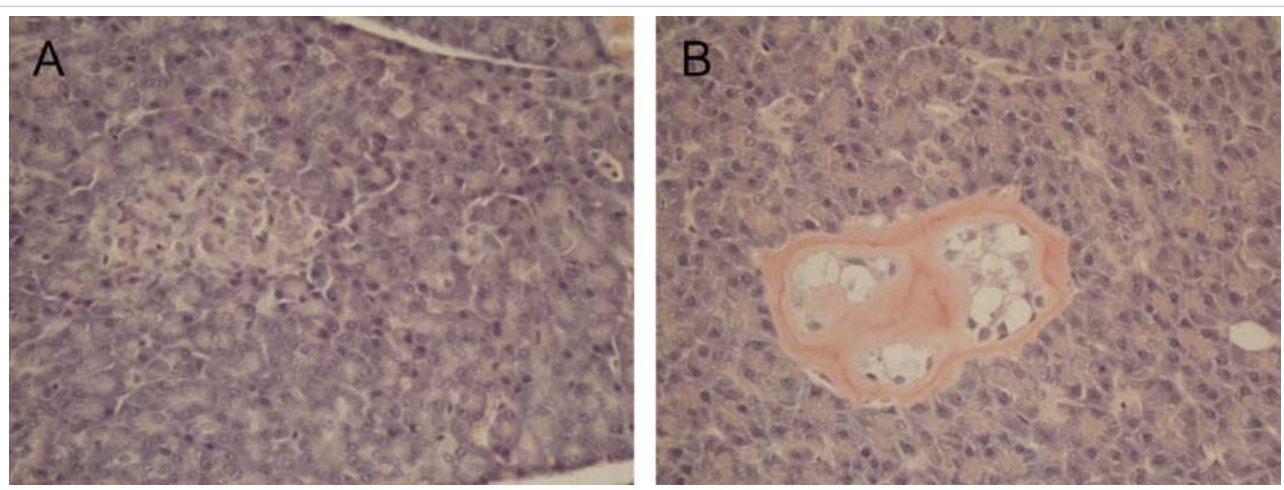

Figure 1: Representative images of Congo red staining on pancreatic sections from healthy cat (A) and diabetic cat (B). Islets in the diabetic cats stained positively with Congo red. 
were then dehydrated in $70 \%$ ethanol for $30 \mathrm{~s}$, in $95 \%$ ethanol for $30 \mathrm{~s}$, and finally in absolute ethanol for $30 \mathrm{~s}$. The frame slide was air dried before laser microdissection performed with a Leica LMD6000 B microscope (Leica Microsystems). Islets were identified with both bright-field and fluorescence microscopy (Figure 2 and 3). The cutting parameters with a 20x objective were set on: laser power 25 , aperture 17 , speed 20 and specimen balance 25. Approximately 2 million $\mu^{2}$ of islet tissue was selected for each sample (two separate samples were collected from each cat) and approximately 2 million $\mu \mathrm{m}^{2}$ of exocrine pancreatic tissue was collected from healthy cat nr.1 The laser microdissected samples were collected in $65 \mu \mathrm{l}$ of lysis buffer (RNeasy Plus Micro Kit, Qiagen, Hilden, Germany) in the cap of a $0.5 \mathrm{ml}$ RNase free microfuge tube (Ambion) during cutting. Thereafter, lysis buffer was added up to $350 \mu \mathrm{l}$ and vortexed thoroughly before storage in $-80^{\circ} \mathrm{C}$.

\section{RNA isolation}

Total RNA was isolated from the laser microdissected feline islets according to the manufacturer's instructions (RNeasy Plus Micro Kit, Qiagen AB). Note that this kit contains a gDNA Eliminator spin column, which will remove the genomic DNA. The amount and purity (OD 260/280) of the total RNA was determined using a NanoDrop 2000C spectrophotometer (Thermo Scientific, Wilmington, DE, USA). Yields of the LMD samples were in the range of 20-26 nanogram RNA. All RNA samples had OD 260/280 between 1.9 and 2.1, which is in the range for pure RNA. Due to the limited amount of isolated RNA, no further quality controls could be included. The extracted total RNA was dissolved in nuclease free water and stored at $-80^{\circ} \mathrm{C}$ until cDNA synthesis. Total RNA from two sets of laser microdissected islets from each cat was isolated.

\section{cDNA synthesis}

The RNA was transcribed to cDNA by Superscript First-Strand Synthesis Super Mix for qRT-PCR (Invitrogen, Life Technologies, Stockholm, Sweden) according to the manufacturer's instructions. Briefly, a mix of random hexamer primers and oligo (dT) primers were incubated with the Superscript III Reverse Transcriptase enzyme mix and RNA at $25^{\circ} \mathrm{C}$ for $10 \mathrm{~min}$, followed by $50^{\circ} \mathrm{C}$ for 30 min and thereafter $85^{\circ} \mathrm{C}$ for $5 \mathrm{~min}$ to inactivate the enzyme. To remove the RNA template from the cDNA:RNA hybrid molecule after first-strand synthesis, the mixture was incubated with two units of RNase $\mathrm{H}$ at $37^{\circ} \mathrm{C}$ for $20 \mathrm{~min}$. The cDNA was stored at $-20^{\circ} \mathrm{C}$ until use for qPCR. Two independent reverse transcriptase reactions were carried out for each RNA sample.

\section{Primers}

Primer pair selection criteria were set to generate short amplicons of 71-220 base pairs (bp) with an annealing temperature of $60^{\circ} \mathrm{C}$ and without predicted dimer formation using Primer BLAST (NCBI). For primer sequences used in this study see Table 1 . The primers were purchased from SigmaAldrich and dissolved in nuclease free water (Ambion). A stock solution of each primer of $100 \mu \mathrm{M}$ was prepared. From the stock solution, a working dilution of $10 \mu \mathrm{M}$ was prepared.
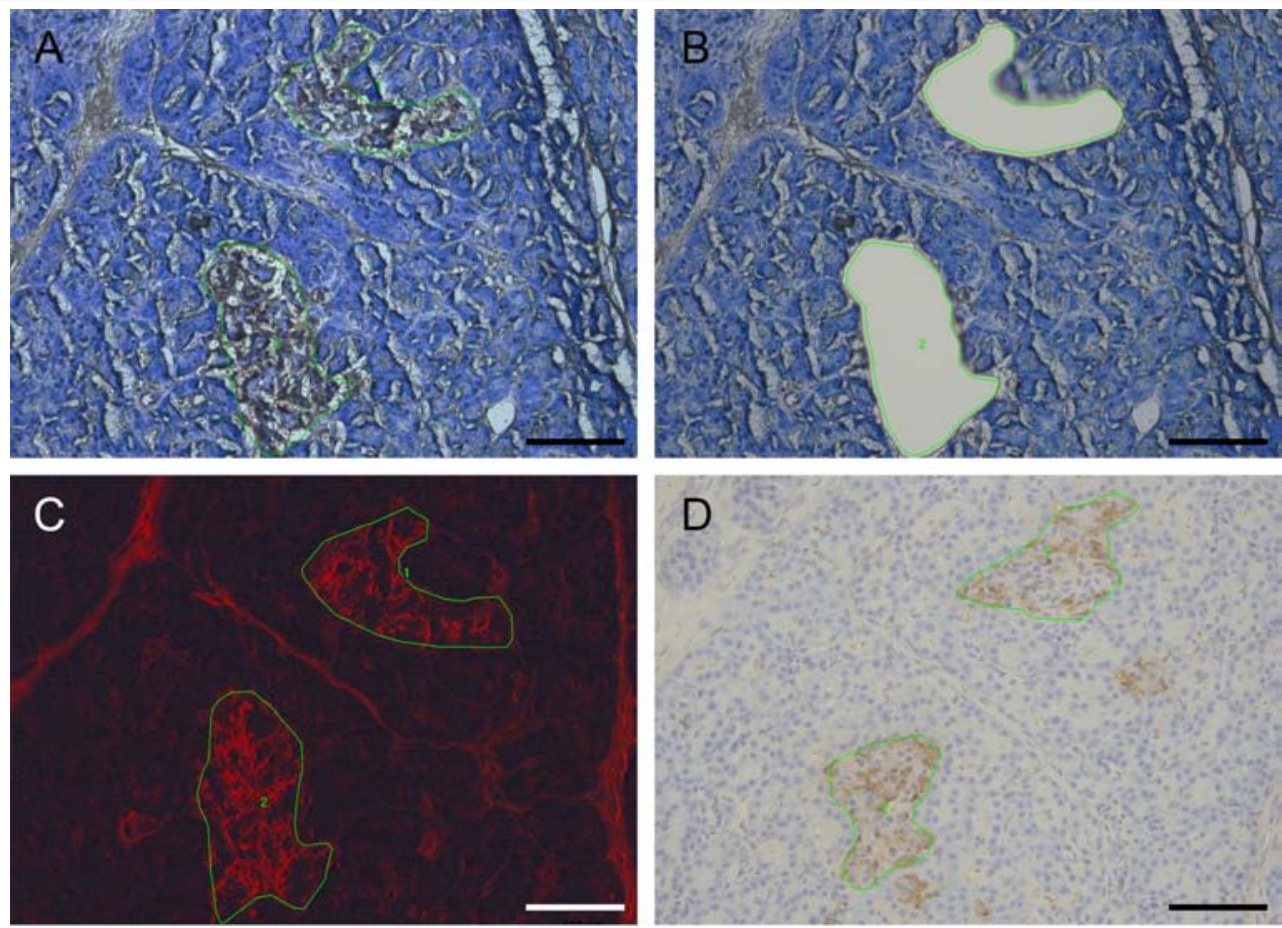

Figure 2: Micrographs of frozen pancreatic tissue from healthy cat

RNase free hematoxylin staining visualizing islets (marked with green line) in (A). Only selected area is laser microdissected (B). With fluorescence, the islets are clearly distinguished from connective tissue (C). Insulin (brown) is visualized with DAB (D). Scale bars represent $100 \mu \mathrm{m}$. 


\section{Quantitative real-time PCR}

The qPCR assay was performed using a Light Cycler 480t (Roche Diagnostic, Mannheim, Germany) and Light Cycler FastStart DNA Master PLUS SYBR Green I kit (Roche Diagnostic) for detection. The final reaction volume of $10 \mu \mathrm{l}$ contained $0.5 \mu \mathrm{M}$ of each primer, $2 \mu \mathrm{l} 5 \mathrm{x}$ Light Cycler FastStart DNA Master PLUS SYBR Green mix, 5 $\mu \mathrm{l}$ water and $0.5 \mathrm{ng}$ of cDNA. In the Non-Template Control (NTC), cDNA was substituted with nuclease free water. Samples without reverse transcriptase were also included. The qPCR reactions were carried out using an initial step of $10 \mathrm{~min}$ at $95^{\circ} \mathrm{C}$ to activate the Taq polymerase, followed by 45 cycles consisting of $10 \mathrm{~s}$ at $95^{\circ} \mathrm{C}, 5 \mathrm{~s}$ at $55^{\circ} \mathrm{C}$, and elongation at $72^{\circ} \mathrm{C}, 10 \mathrm{~s}$. The fluorescence was measured at the end of each cycle. A melting curve analysis was performed directly following PCR by continuously reading the fluorescence while slowly heating the reactions from $65^{\circ} \mathrm{C}$ to $95^{\circ} \mathrm{C}$. All qPCR samples were run in duplicates. Moreover, cDNA was prepared twice from each RNA sample to ensure inter run specificity. In summary, all samples were run in quadruplicates per gene and RNA preparation, and thus eight samples per cat. To determine the PCR efficiency, the primer pairs were analyzed using a dilution curve with ten-fold cDNA template dilutions between $2 \mathrm{ng} / \mu \mathrm{l}$ and $0.02 \mathrm{ng} / \mu \mathrm{l}$. The efficiency was calculated using the formula: Efficiency $=-1+10^{(-1 / \text { slope })}$. As markers for islets, we selected the genes insulin (INS), Pancreatic and Duodenal Homeobox 1 (PDX1), Chromogranin A (CHGA), Islet Cell Antigen 2 (IA-2) and Islet Amyloid Polypeptide (IAPP) (Table 2). Pancreatic Lipase (PNLIP) was selected as a marker for exocrine pancreatic tissue. The expression stability of reference transcripts BetaActin (ACTB), Glyceraldehyde-3-phosphatase Dehydrogenase (GAPDH) and Ribosomal Protein 7 (RPS7) was evaluated using the Normfinder software [22]. The results are presented as Threshold Cycle values (Ct-values). The Ct-values were used to calculate the amount of PCR product compared with reference genes by subtracting the Ct-value for reference genes from the Ctvalue for the gene studied $(\Delta \mathrm{Ct})$. Relative mRNA expression was calculated as $2^{-\Delta C t}$. Data are expressed as means of two islet LMD preparations from each cat \pm SEM.

\section{Agarose gel-electrophoresis}

To confirm amplicon size, qPCR products were analyzed by electrophoresis using 3\% agarose gel (PCR-grade, Bio-Rad, Hercules, CA, USA). The PCR products were mixed with $5 \mathrm{x}$ loading buffer (Bio-Rad) before loading. A 50 bp ladder (Invitrogen) was used to determine the size of the PCR products. Electrophoresis was conducted using an electrical field of $5 \mathrm{~V} / \mathrm{cm}$ for $80 \mathrm{~min}$ and the bands were visualized using GelRed (Biotium, Hayward, CA, USA) and detected using the Chemi Doc MP Imaging System (Bio-Rad).

\section{Immunohistochemistry}

Separate frozen pancreas sections were mounted on polysine coated glass slides (Thermo Scientific) and stored in the $-80^{\circ} \mathrm{C}$ freezer. Sections were fixed in zinc fixative (IHC Zinc fixative (formalin free), BD Pharmingen, San Diego, CA, USA) for $10 \mathrm{~min}$ electrophoresis using a room temperature before peroxidase blocking (Dako REAL Peroxidase-Blocking Solution, Glostrup, Denmark) for $5 \mathrm{~min}$ and thereafter protein block (Background Sniper, Biocare Medical, Concord, CA, USA) for $10 \mathrm{~min}$. Sections were incubated with primary antibody (Guinea pig polyclonal insulin antibody, dilution 1:400, Fitzgerald, Concord, MA, USA) overnight in the refrigerator. A Horseradish Peroxidase (HRP) polymer system was used according to the manufacturer's instructions (MACH 3 Rabbit HRP Polymer detection, Biocare Medical). Sections were developed in Diaminobenzidine (DAB) and counterstained with hematoxylin. After dehydration, sections were mounted with pertex (Histolab, Göteborg, Sweden). Dako wash buffer was used in all wash steps.

Table 1: Feline primer data.

\begin{tabular}{|c|c|c|c|}
\hline Gene & Oligo & Sequence $\left(5^{\prime}-3^{\prime}\right)$ & Amplicon size (bp) \\
\hline$A C T B$ & $\begin{array}{l}\text { forward } \\
\text { reverse }\end{array}$ & $\begin{array}{l}\text { GTGGATCAGCAAGCAGGAGT } \\
\text { CACTTGCCAGGGCAAACCTA }\end{array}$ & 136 \\
\hline GAPDH & $\begin{array}{l}\text { forward } \\
\text { reverse }\end{array}$ & $\begin{array}{l}\text { GCCATCAATGACCCCTTCAT } \\
\text { GCCGTGGAATTTGCCGT }\end{array}$ & 82 \\
\hline RPS7 & $\begin{array}{l}\text { forward } \\
\text { reverse }\end{array}$ & $\begin{array}{l}\text { AAAATCCAAGTCCGGCTCGT } \\
\text { TCACACGGATTCTCTTGCCC }\end{array}$ & 220 \\
\hline INS1 & $\begin{array}{l}\text { forward } \\
\text { reverse }\end{array}$ & $\begin{array}{l}\text { CATCGTGGAGCAATGCTGTG } \\
\text { GCGCCCTCTAGTTGCAGTAA }\end{array}$ & 71 \\
\hline$I A P P$ & $\begin{array}{l}\text { forward } \\
\text { reverse }\end{array}$ & $\begin{array}{l}\text { AGAAGCAATGTGCCTCCTGA } \\
\text { AGAAATTTGCCAGGCGTTGG }\end{array}$ & 152 \\
\hline$I A-2$ & $\begin{array}{c}\text { forward } \\
\text { reverse }\end{array}$ & $\begin{array}{l}\text { CCAAGGGCTCAGGACGAAAT } \\
\text { GATCCAGAGATCAGCACCCG }\end{array}$ & 190 \\
\hline CHGA & $\begin{array}{c}\text { forward } \\
\text { reverse }\end{array}$ & $\begin{array}{l}\text { ACACACTATCCAAGCCCAGC } \\
\text { GGCACCTTGGAGAGCAAGAT }\end{array}$ & 137 \\
\hline$P D X 1$ & $\begin{array}{l}\text { forward } \\
\text { reverse }\end{array}$ & $\begin{array}{l}\text { AAGTCTACCAAGGCTCACGC } \\
\text { TGCGTGTCCGTTTGTTTTCC }\end{array}$ & 85 \\
\hline PNLIP & $\begin{array}{l}\text { forward } \\
\text { reverse }\end{array}$ & $\begin{array}{l}\text { CAAACAAGTGCTTCCCCTGC } \\
\text { TTCCTTCCAGACAGCGTGAC }\end{array}$ & 172 \\
\hline
\end{tabular}


Table 2: Specifications of the tested feline genes including reference genes.

\begin{tabular}{|c|l|l|c|}
\hline Gene & \multicolumn{1}{|c|}{ Name } & \multicolumn{1}{|c|}{ Function } & GenBank Acc. Nr. \\
\hline$A C T B$ & beta-Actin & Major cytoskeletal protein & XM_003997266 \\
\hline CHGA & Chromogranin A & Secreted protein produced by endocrine cells & XM_003987967 \\
\hline GAPDH & Glyceraldehyde 3-phosphate dehydrogenase & Glycolytic enzyme & NM_001009307 \\
\hline$I A-2$ & $\begin{array}{l}\text { Islet cell antigen 2, receptor-type tyrosine- } \\
\text { protein phosphatase-like N isoform 2 }\end{array}$ & Receptor-type tyrosine-protein phosphatase & XM_003991192 \\
\hline$I A P P$ & Islet amyloid polypeptide & Secreted peptide produced by beta cells & NM_001043338 \\
\hline$I N S$ & Insulin & Peptide hormone, lowers blood glucose & NM_001009272 \\
\hline PDX1 & Pancreatic and duodenal homeobox 1 & $\begin{array}{l}\text { Transcription factor, beta cell differentiation } \\
\text { marker }\end{array}$ & XM_003980305 \\
\hline RPS7 & Ribosomal protein S7 & Ribosomal protein & NM_001009832 \\
\hline PNLIP & Pancreatic lipase & Enzyme produced in exocrine pancreas & XM_006938207 \\
\hline
\end{tabular}
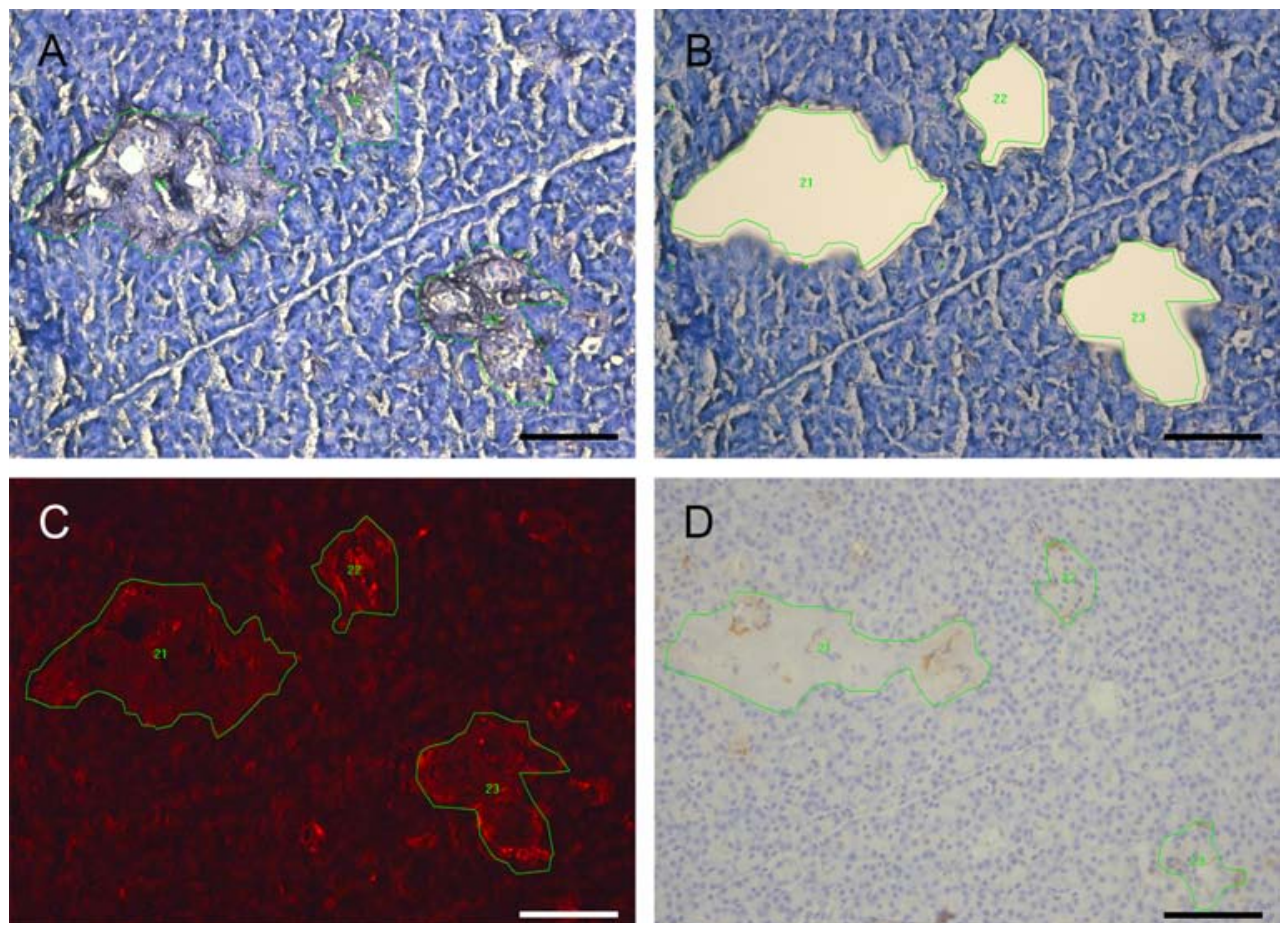

Figure 3: Micrographs of frozen pancreatic tissue from diabetic cat

RNase free hematoxylin staining visualizing islets (marked with green line) in (A). Only selected area is laser microdissected (B). Islets are visualized by fluorescence with a Texas Red filter (C). Insulin (brown) is visualized with DAB (D). Scale bars represent $100 \mu \mathrm{m}$.

\section{Results}

\section{Laser microdissection of islets and immunohisto- chemistry}

By the use of RNase-free hematoxylin to stain frozen pancreatic cat tissue for 90 seconds, we were able to identify islets for laser microdissection (Figure 2A and $3 \mathrm{~A}$ ). We found that islets showed fluorescence visualized with a Texas Red filter (Figure 2C and $3 \mathrm{C}$ ). Connective tissue, which also showed fluorescence, was distinguished from islets by its characteristic fibrous appearance. The selected islets could therefore be distinctly cut out without visible contamination with exocrine pancreatic tissue (Figure 2B and 3B). Separate pancreatic sections from adjacent areas used to stain for insulin with Immunohistochemistry (IHC) revealed high insulin content in islets of healthy cats (Figure 2D) whereas less insulin-positive cells were found in diabetic cats (Figure 3D).

\section{Specificity of the islet-specific genes used in the qPCR assay}

Primers for qPCR were designed using PrimerBlast (NCBI). The specificity of each primer pair (Tables 1 and 2) was verified by melting curve analysis followed by gel-electrophoresis. A 
single specific peak in the melting curve from each primer pair indicates that the qPCR has only amplified one product (data not shown). The detected Melting Temperatures (Tm) had a PCR product-specific variation of less than $0.3^{\circ} \mathrm{C}$. All qPCR reactions were then analyzed by agarose gel-electrophoresis (Figures $4 \mathrm{~A}$ and $4 \mathrm{~B}$ ), which confirmed that each primer pair was specific for the cDNA. A single band at the expected size of the amplicon for each primer pair could be detected. The non-template control where the cDNA was substituted with water, confirms the absence of primer dimers (data not shown). In the samples where the reverse transcription step was omitted, no amplified product could be detected (data not shown). This confirms that genomic DNA did not interfere with the PCR results.

\section{Efficiency of the PCR}

To determine the PCR efficiency, the primer pairs were further analyzed using a dilution curve with ten-fold cDNA template dilutions between $2 \mathrm{ng} / \mu \mathrm{l}$ and $0.02 \mathrm{ng} / \mu \mathrm{l}$. The PCR efficiency of the primer pairs was determined to be in the range of 90 to $100 \%$ (data not shown).

\section{Transcript levels of islet-specific genes}

The normalization analysis, using the Normfinder software, indicated that the best normalization was obtained by using the geometric mean of the expression of the reference genes GAPDH and RPS7. This normalization was used to compare the islet-specific transcripts in all samples. To characterize the islets collected by laser microdissection from two healthy and two diabetic cats, the normalized mRNA expression levels of INS, PDX1, CHGA, IA-2 and IAPP were determined (Figure 5) and compared. Within and between run variations were found to be low/moderate and reproducible results were obtained.

\section{Purity of islet preparation}

In order to investigate the purity of the LMD islets we performed qPCR on healthy cat nr 1 using the primers for PNLIP. It is highly expressed in the exocrine tissue of the pancreas but is expressed at very low levels in islets [23]. The islet sample was compared to an LMD sample of exocrine pancreatic tissue.

The signal for the exocrine control gene PNLIP was 82 times higher in the exocrine tissue compared to islets. This indicates that the islet preparation contains less than $1.2 \%$ exocrine cells (Figure 6).

\section{Discussion}

In the present study, we demonstrate that laser microdissection allows distinct isolation of pancreatic islets from both healthy and diabetic cats, with preserved RNA integrity for further studies, i.e. gene expression profiling. Feline islets have been considered particularly difficult to isolate with standard collagenase protocols due to a lack of peri-islet matrix, and previous isolation attempts have resulted in islets surrounded by a rim of exocrine tissue $[10,11,24]$. It is advantageous to minimize the amount of exocrine tissue contamination when performing gene expression studies on pancreatic islets.

In order to prevent degradation of RNA we tried to keep the staining protocol as short as possible. We found that a staining time of $90 \mathrm{~s}$ was optimal for visualization of islets, as compared to the slightly shorter staining protocols used for isolation of rodent islets $[17,25]$, or as in human islet laser microdissection, where the intrinsic autofluorescence of human $\beta$-cells allows isolation without prior staining [13-15]. The autofluorescence of rodent $\beta$-cells is not strong enough to be useful for LMD [17], and although we found fluorescence of stained feline islets using the Texas red filter, this fluorescence was not strong enough to be used without staining of slides to allow for identification and isolation of islets.

We found mRNA expression of all islet-specific genes, as well as the reference genes, in all our samples. As markers for islets, we selected the genes INS, PDX1, CHGA, IA-2 and IAPP. Since islets in majority consist of beta cells [9], we wanted to investigate the mRNA levels of insulin. PDX1 is a transcription factor, which is important in the maturation and survival of beta cells [26], CHGA is
A

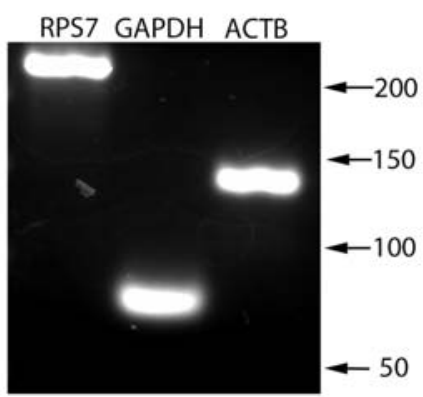

B

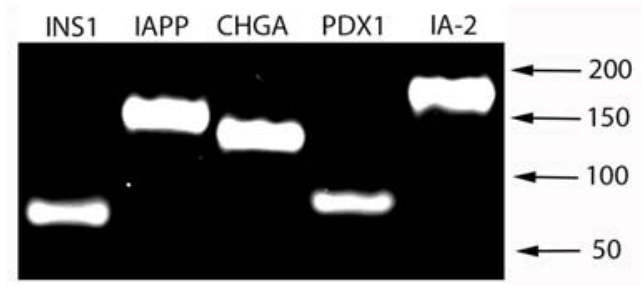

Figure 4: Specificity of the reference genes and islet-specific genes used in the qPCR assay qPCR products from the reference genes visualized on a $3 \%$ agarose gel stained with GelRed. Each primer pair was subjected to PCR using reverse transcribed total RNA as template. All primer pairs generated a single product of the predicted size. Arrows indicate DNA molecular ladder (bp). (A) Lane 1: primer for RPS7 (220 bp). Lane 2: primer for GAPDH (82 bp). Lane 3: primer for ACTB (136 bp). (B) Lane 1: primers for INS (71 bp). Lane 2: primers for IAPP (152 bp). Lane 3: primers for CHGA (137 bp). Lane 4: primers for PDX1 (85 bp). Lane 5: primers for IA-2 (190 bp). 

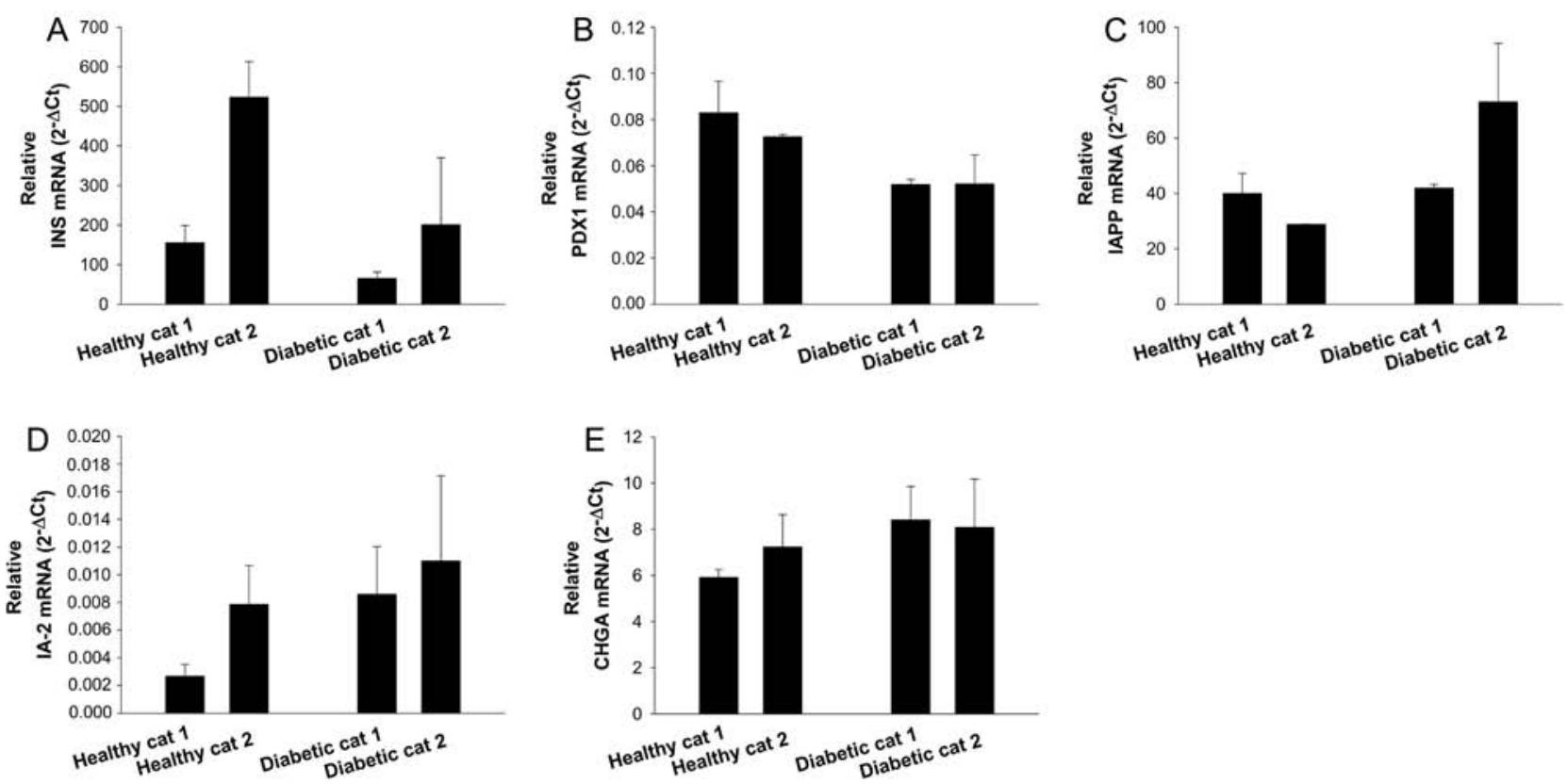

Figure 5: Relative mRNA transcript levels in laser microdissected feline islets from healthy and diabetic cats

Relative gene expression for INS (A), PDX1 (B), IAPP (C), IA-2 (D) and CHGA (E) in two healthy and two diabetic cats. Values are normalized to the geometric mean of the reference genes RPS7 and GAPDH. Data are expressed as means of two islet LMD preparations from each cat \pm SEM.
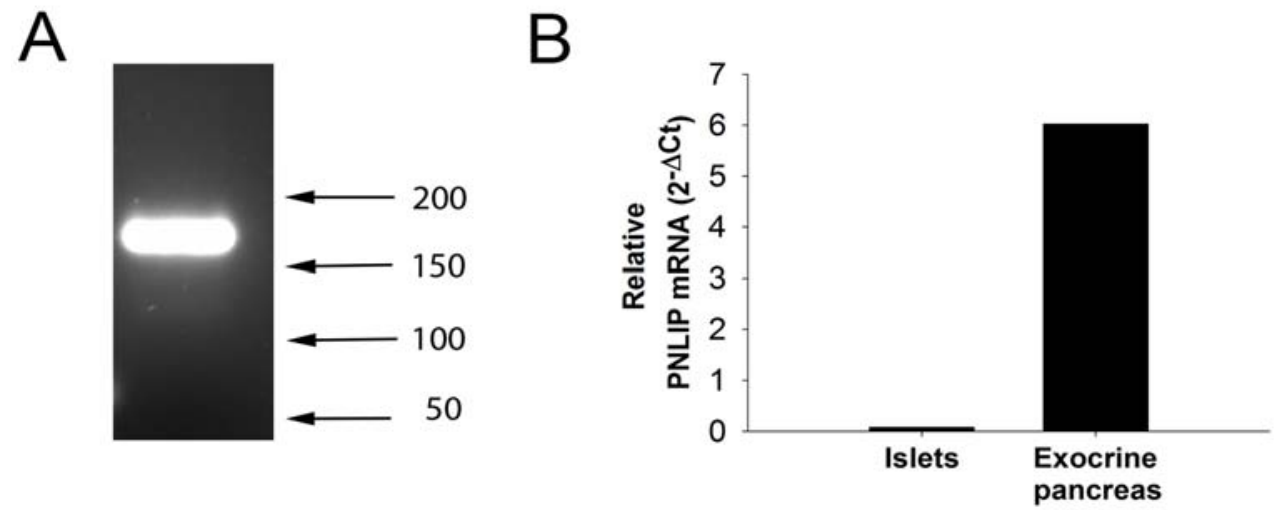

Figure 6: Purity of islet preparation

(A) Specificity of the exocrine pancreatic gene used in the qPCR assay and relative mRNA transcript levels in laser microdissected feline islets and exocrine pancreatic tissue. qPCR product from the exocrine gene visualized on a 3\% agarose gel stained with GelRed. The primer pair was subjected to PCR using reverse transcribed total RNA as template. The primer pair generated a single product of the predicted size. Arrows indicate DNA molecular ladder (bp). Lane 1: primer for PNLIP (172 bp). (B) Relative gene expression for PNLIP in islets and exocrine tissue from healthy cat no 1. Values are normalized to the reference gene RPS7.

a general marker for endocrine cells, whereas IA-2, (also referred as Islet Cell Autoantigen (ICA) 512) is an islet-specific membrane protein found in all islet endocrine cells [27]. Moreover, IA-2 is also well known as a diabetes-specific autoantigen [28]. CHGA and IA-2 were included in our study in case we could not detect the mRNA levels of insulin in the diabetic cats. Aggregates of IAPP result in amyloid formation in islets, which is found in diabetic cats, as well as in humans with T2DM [8]. Congo red staining on pancreatic sections from diabetic cats confirmed presence of amyloid in islets, whereas islets from healthy cats were not stained with Congo red.

Great care was taken, only to include the visible islets themselves in the laser microdissection while carefully avoiding exocrine tissue, and by cutting out all islets under direct surveillance. Moreover, PNLIP was included in the study as an 
exocrine control. Our islet preparation was found to be pure with as low as $1.2 \%$ of exocrine cells.

One of the diabetic cats (nr.1) showed, as expected, a lower expression of insulin compared to both healthy cats, whereas the other diabetic cat (nr. 2) showed expression of insulin in the same range as the healthy cats. This could be explained by the first cat being in a later stage of the disease, with a declining insulin secretion; whereas the second cat was more recently diagnosed and may still have had a normal insulin production. Measuring circulating serum insulin levels may help elucidate these observations, and no conclusions could be drawn from this finding due to the small number of cats included in the study.

Immunohistochemistry was used to confirm presence of insulin-positive cells in pancreatic specimens. We found, not surprisingly, that these cells were more abundant in healthy cats than in diabetic cats. The immunohistochemistry slides were prepared from sections in close proximity to the laser microdissected sections and thus help verifying the presence and location of islets.

Laser microdissection allows distinct studies of islets with minimal contamination of acinar cells. Our results demonstrate that laser microdissected islets both from healthy and diabetic cats can effectively be utilized for quantitative PCR studies. Future studies using LMD and q-PCR will help define expression profiles of healthy and diabetic cats. We are currently recruiting additional healthy and diabetic cats in order to expand the study and investigate a larger set of genes important in islet function. Differences in gene expression between healthy and diabetic cats may reveal underlying mechanisms for beta cell dysfunction and decreased beta cell mass in human T2DM.

\section{Acknowledgement}

The study was generously supported by the Swedish Juvenile Diabetes Foundation, the Fredrik and Ingrid Thuring's Foundation, the Magnus Bergvall's Foundation, the Lars Hierta's Memorial Foundation, and the Foundation for Research, Agria Insurance Company and the Swedish Kennel Club. We thank Erika Karlstam (DVM, Dipl. ECVP), for the post-mortem examinations.

\section{References}

1. Cefalu WT. Animal models of type 2 diabetes: Clinical presentation and pathophysiological relevance to the human condition. ILAR J. 2006; 47(3): 186-98.

2. Henson MS, O'Brien TD. Feline models of type 2 diabetes mellitus. ILAR J, 2006; 47(3): 234-42.

3. Linsenmeier RA, Braun RD, McRipley MA, Padnick LB, Ahmed J, Hatchell DL, et al. Retinal hypoxia in long-term diabetic cats. Invest Ophthalmol Vis Sci. 1998; 39(9): 1647-57.

4. Mizisin AP, Shelton GD, Burgers ML, Powell HC, Cuddon PA, et al. Neurological complications associated with spontaneously occurring feline diabetes mellitus. J Neuropathol Exp Neurol. 2002; 61(10): 87284.

5. Johnson KH, Hayden DW, O’Brien TD, Westermark P, et al. Spontaneous diabetes mellitus-islet amyloid complex in adult cats. Am J Pathol. 1986; 125(2): 416-9.

6. Lutz TA, Rand JS. Detection of amyloid deposition in various regions of the feline pancreas by different staining techniques. J Comp Pathol. 1997; 116(2): 157-70.

7. Butler AE, Janson J, Bonner-Weir S, Ritzel R, Rizza RA, Butler PC, et al. Beta-cell deficit and increased beta-cell apoptosis in humans with type 2 diabetes. Diabetes. 2003; 52(1): 102-10.

8. Ma Z, Westermark GT, Johnson KH, O'Brien TD, Westermark P, et al. Quantitative immunohistochemical analysis of islet amyloid polypeptide (IAPP) in normal, impaired glucose tolerant and diabetic cats. Amyloid. 1998; 5(4): 255-61.

9. O’brien TD, Hayden DW, Johnson KH, Fletcher TF. Immunohistochemical morphometry of pancreatic endocrine-cells in diabetic, normoglycemic glucose-intolerant and normal cats. J Comp Pathol. 1986; 96(4): 357-69.

10.Zini E, Franchini M, Guscetti F, Osto M, Kaufmann K, Ackermann $\mathrm{M}$, et al. Assessment of six different collagenase-based methods to isolate feline pancreatic islets. Res Vet Sci. 2009; 87(3): 367-72. doi: 10.1016/j.rvsc.2009.03.017

11. Maeno T, Inoue M, Embabi SN, Miki D, Hatchell DL. Islet-like cell clusters: viability, cell types, and subretinal transplantation in pancreatectomized cats. Lab Anim. 2006; 40(4): 432-46.

12. Franchini M, Zini E, Osto M, Jablonski K, Kaufmann K, Lutz TA, et al. Feline pancreatic islet-like clusters and insulin producing cells express functional Toll-like receptors (TLRs). Vet Immunol and Immunopathol. 2010. 138(1-2): 70-78. doi: 10.1016/j.vetimm.2010.07.001.

13. Marselli L, Thorne J, Ahn YB, Omer A, Sgroi DC, Libermann T, et al Gene expression of purified beta-cell tissue obtained from human pancreas with laser capture microdissection. J Clin Endocrinol Metab. 2008; 93(3): 1046-53.

14. Marselli L, Sgroi DC, Bonner-Weir S, Weir GC. Laser capture microdissection of human pancreatic beta-cells and RNA preparation for gene expression profiling. Methods Mol Biol. 2009; 560: 87-98. doi: 10.1007/978-1-59745-448-3_8.

15. Marselli L, Thorne J, Dahiya S, Sgroi DC, Sharma A, Bonner-Weir S, et al, Gene Expression Profiles of Beta-Cell Enriched Tissue Obtained by Laser Capture Microdissection from Subjects with Type 2 Diabetes. PLoS One. 2010; 5(7). e11499. doi: 10.1371/journal.pone.0011499.

16. Laybutt DR, Kaneto H, Hasenkamp W, Grey S, Jonas JC, Sgroi DC, et al, Increased Expression of Antioxidant and Antiapoptotic Genes in Islets That May Contribute to beta-Cell Survival During Chronic Hyperglycemia. Diabetes. 2002; 51(2): 413-23.

17. Dreja T, Jovanovic Z, Rasche A, Kluge R, Herwig R, Tung YC, et al. Dietinduced gene expression of isolated pancreatic islets from a polygenic mouse model of the metabolic syndrome. Diabetologia. 2010; 53(2): 309-20. doi: 10.1007/s00125-009-1576-4.

18. Sturm D, Marselli L, Ehehalt F, Richter D, Distler M, Kersting S, et al. Improved protocol for laser microdissection of human pancreatic islets from surgical specimens. J Vis Exp. 2013; 71: 50231. doi: $10.3791 / 50231$.

19. Rios L, Ward C. Feline diabetes mellitus: diagnosis, treatment, and monitoring. Compend Contin Educ Vet. 2008; 30(12): 626-39.

20. Puchtler H, Sweat F, Levine M. On the binding of Congo red by amyloid. J Histochem Cytochem. 1962; 10(3): 355-64. doi: 10.1177/10.3.355 
21. Furuzawa Y, Ohmori $Y$, Watanabe T. Immunohistochemical morphometry of pancreatic islets in the cat. J Vet Med Sci, 1992; 54(6): 1165-73.

22. Andersen CL, Jensen JL, Ørntoft TF. Normalization of Real-Time Quantitative Reverse Transcription-PCR Data: A Model-Based Variance Estimation Approach to Identify Genes Suited for Normalization, Applied to Bladder and Colon Cancer Data Sets. Cancer Res. 2004; 64(15): 5245-50.

23. Eizirik DL, Sammeth M, Bouckenooghe T, Bottu G, Sisino G, IgoilloEsteve M, et al. The human pancreatic islet transcriptome: expression of candidate genes for type 1 diabetes and the impact of proinflammatory cytokines. PLoS Genet, 2012. 8(3): 1002552. doi: 10.1371/journal.pgen.1002552.

24.Zini E, Franchini M, Osto M, Vögtlin A, Guscetti F, Linscheid P, et al. Quantitative real-time PCR detection of insulin signalling-related genes in pancreatic islets isolated from healthy cats. Vet J. 2010;
183(3): 287-93. doi: 10.1016/j.tvjl.2008.11.012.

25. Jermendy A, Toschi E, Aye T, Koh A, Aguayo-Mazzucato C, Sharma A, et al. Rat neonatal beta cells lack the specialised metabolic phenotype of mature beta cells. Diabetologia. 2011; 54(3): 594-604. doi: 10.1007/ s00125-010-2036-x.

26. Fujimoto K, Polonsky KS. Pdx1 and other factors that regulate pancreatic beta-cell survival. Diabetes Obes Metab. 2009; 11 Suppl 4: 30-7. doi: 10.1111/j.1463-1326.2009.01121.x.

27. Solimena, M, Dirkx R Jr, Hermel JM, Pleasic-Williams S, Shapiro JA, Caron L, et al. ICA 512, an autoantigen of type I diabetes, is an intrinsic membrane protein of neurosecretory granules. EMBO J. 1996; 15(9): 2102-14.

28. Rabin DU, Pleasic SM, Shapiro JA, Yoo-Warren H, Oles J, Hicks JM, et al. Islet-cell antigen-512 is a diabetes-specific islet autoantigen related to protein-tyrosine phosphatases. J Immunol. 1994; 152(6): 3183-88. 